\title{
How to Obtain a Dermatology Residency: A Guide Targeted to Underrepresented in Medicine Medical Students
}

\author{
Jennifer N. Rorex, MD; Nkanyezi Ferguson, MD; Roopal V. Kundu, MD
}

\section{PRACTICE POINTS}

- Students interested in dermatology are encouraged to seek mentorship, strive for their academic best, and maintain their unique personal interests that make them a well-rounded applicant.

- Increasing diversity in dermatology requires initiative from students as well as dermatologists who are willing to mentor and sponsor.

Efforts to increase diversity have been put forth by the Skin of Color Society (SOCS) to assist underrepresented in medicine (UIM) students during their pursuit of dermatology. Increasing diversity in dermatology relies on efforts from students and mentors established in dermatology. This article highlights and summarizes key guidelines from the socs.

Cutis. 2020;106:12-13.

7 here has been increasing attention focused on the lack of diversity within dermatology academic and residency programs. ${ }^{1-6}$ Several factors have been identified as contributing to this narrow pipeline of qualified applicants, including lack of mentorship, delayed exposure to the field, implicit bias, and lack of an overall holistic review of applications with overemphasis on board scores. ${ }^{1,5}$ In an effort to provide guidance to underrepresented in medicine (UIM) students who are interested in dermatology, the Skin of Color Society (SOCS) has created a detailed, step-by-step guide on how to obtain a position in a dermatology residency program, ${ }^{7}$ which was modeled after a similar resource created by the American Academy of Orthopaedic Surgeons. ${ }^{8}$ Here, we highlight the main SOCS recommendations to help guide medical students through a systematic approach to becoming successful applicants for dermatology residency.

\section{Start Early}

Competitive fields such as dermatology require intentional efforts starting at the beginning of medical school. Regardless of what specialty is right for you, begin by constructing a well-rounded application for residency immediately. Start by shadowing dermatologists and attending Grand Rounds held in your institution's dermatology department to ensure that this field is right for you. Students are encouraged to meet with academic advisors and upperclassmen to seek guidance on gaining early exposure to dermatology at their home institutions (or nearby programs) during their first year. As a platform for learning about community-based dermatology activities, join your school's Dermatology Interest Group, keeping in mind that an executive position in such a group can help foster relationships with faculty and residents of the dermatology department. A long-term commitment to community service also contributes to your depth as an applicant. Getting involved early helps students uncover health disparities in medicine and allows time to formulate ideas to implement change. Forming a wellrounded application mandates maintaining good academic standing, and students should prioritize mastering the curriculum, excelling in clinical rotations, and studying for the US Medical Licensing Examination (USMLE).

\section{Choose a Mentor}

The summer between your first and second years of medical school is an opportune time to explore research opportunities. Students successfully complete research by taking ownership of a project, efficiently meeting deadlines, maintaining contact with research mentors by quickly responding to emails, and producing quality work. Research outside of dermatology also is valued. Research mentors often provide future letters of recommendation, so commit to doing an outstanding job. For those finding it difficult to locate a mentor, consider searching the American Academy of

Dr. Rorex is from Boonshoft School of Medicine, Wright State University, Dayton, Ohio. Dr. Ferguson is from the Department of Dermatology, University of lowa Hospitals and Clinics, lowa City. Dr. Kundu is from the Department of Dermatology, Northwestern University Feinberg School of Medicine, Chicago, Illinois. The authors report no conflict of interest.

Correspondence: Roopal V. Kundu, MD, Department of Dermatology, Northwestern University Feinberg School of Medicine, 676 North St Clair St, Ste 1600, Chicago, IL 60611 (roopal.kundu@nm.org). 
Dermatology (AAD)(https://www.aad.org/mentorship/) or SOCS (https://skinofcolorsociety.org/) websites. The AAD has an established Diversity Mentorship Program (https://www.aad.org/member/career/volunteer/diversity -mentorship) that provides members with direct guidance from dermatologists for 4 weeks. Students use this time to conduct research, learn more about the specialty, and foster a relationship with their mentor. Students can apply any year of medical school; however, the typical awardee usually is a third-year or fourth-year student. The AAD may provide a stipend to help offset expenses.

\section{Prepare for Boards}

Second year is a continuation of the agenda set forth in first year, now with the focus shifting toward board preparation and excelling in clinical core didactics and rotations. According to data from the 2018 National Resident Matching Program, ${ }^{9}$ the mean USMLE Step 1 score for US allopathic senior medical students who matched into dermatology was 249 compared to 241 who did not match into dermatology. However, the mean score is just that-a mean-and people have matched with lower scores. Do not be intimidated by this number; instead, be driven to commit the time and resources to master the content and do your personal best on the USMLE Step examinations. Given the shift in some programs for earlier clinical exposure and postponement of boards until the third year, the recommendations in this timeline can be catered to fit a medical student's specific situation.

\section{Build Your Application}

The third year of medical school is a busy year. Prepare for third-year clinical rotations by speaking with upperclassmen and clinical preceptors as you progress through your rotations. Evaluations and recommendations are weighed heavily by residency program directors, as this information is used to ascertain your clinical abilities. Seek feedback from your preceptors early and often with a sincere attempt to integrate suggested improvements. Schedule a dermatology rotation at your home institution after completing the core rotations. Although they are not required, applicants may complete away rotations early in their fourth year; the application period for visiting student learning opportunities typically opens April 1 of the third year, if not earlier. Free resources are available to help prepare for your dermatology rotations. Start by reviewing the Basic Dermatology Curriculum on the AAD website (https://www.aad.org/member/education /residents/bdc). Make contributions to your Electronic Residency Application Service account by thinking about letter writers, your personal statement, scheduling the USMLE Step 2, and completing any pending publications.

\section{Interviewing for Residency}

During your fourth year of medical school, you will be completing dermatology rotations, submitting your applications through the Electronic Residency Application Service, and interviewing with residency programs. When deciding which programs to apply to, consider referencing the American
Medical Association Residency and Fellowship Database (https://freida.ama-assn.org/Freida/\#/). Also keep in mind that, depending on your competitiveness, you should expect to receive 1 interview for every 10 programs you apply to, thus the application process can be quite costly. It is highly encouraged that you ask for letters of recommendation prior to August 15 and that you submit your applications by September 15. Complete mock interviews with a mentor and research commonly asked questions. Prior to your interview day, you want to spend time researching the program, browsing faculty publications, and reviewing your application. Dress in a comfortable suit, shoes, and minimal accessories; arrive early knowing that your interview begins even before you meet your interviewer, so treat everyone you meet with respect. Refrain from speaking to anyone in a casual way and have questions prepared to ask each interviewer. After your interviews, be sure to write thank you notes or emails if a program does not specifically discourage postinterview communication. Continuous efforts will improve your success in obtaining a dermatology residency position.

\section{Final Thoughts}

Recent articles have underscored and emphasized the importance of diversity in our field, with a call to action to find meaningful and overdue solutions. ${ }^{2,6}$ We acknowledge the important role that mentors play in providing timely, honest, and encouraging guidance to UIM students interested in careers in dermatology. We hope to provide readily available and detailed guidance to these students on how they can present themselves as excellent and qualified applicants through this summary and other platforms.

Acknowledgment-The authors would like to thank the members of the SOCS Diversity Task Force for their assistance in creating the original guide.

\section{REFERENCES}

1. Chen A, Shinkai K. Rethinking how we select dermatology applicantsturning the tide. JAMA Dermatol. 2017;153:259-260.

2. Granstein RD, Cornelius L, Shinkai K. Diversity in dermatology - a call for action. JAMA Dermatol. 2017;153:499-500.

3. Imadojemu $S$, James WD. Increasing African American representation in dermatology. JAMA Dermatol. 2016;152:15-16.

4. Pandya AG, Alexis AF, Berger TG, et al. Increasing racial and ethnic diversity in dermatology: a call to action. J Am Acad Dermatol. 2016;74:584-587.

5. Pritchett EN, Pandya AG, Ferguson NN, et al. Diversity in dermatology: roadmap for improvement. J Am Acad Dermatol. 2018;79:337-341.

6. Taylor SC. Meeting the unique dermatologic needs of black patients [published online August 21, 2019]. JAMA Dermatol. doi:10.1001/ jamadermatol.2019.1963.

7. Skin of Color Society. How to obtain a position in a dermatology residency program. https://skinofcolorsociety.org/wp-content /uploads/2019/10/How-to-Obtain-a-Position-in-a-Dermatology -Residency-Program-10-08-2019.pdf. Accessed June 24, 2020.

8. American Academy of Orthopaedic Surgeons. How to obtain an orthopedic residency by the American Academy of Orthopaedic Surgeons. https://www.aaos.org/globalassets/about/diversity/how-to-obtain -an-orthopaedic-residency.pdf. Accessed June 24, 2020.

9. Results and Data-2018 Main Residency Match. Washington, DC: National Resident Matching Program; 2018. Published April 2018. Accessed June 24, 2020. 